\title{
Linguistic Landscape in Promotion of Language Through Traffic Signboards: An Introduction to the Signs in Pakistani Roads and Highways
}

\author{
Syed Khuram Shahzad ${ }^{1}$, Javed Hussain ${ }^{2}$, Samina Sarwat ${ }^{3}$, Amna Ghulam Nabi ${ }^{4} \&$ M. Mumtaz Ahmed ${ }^{5}$ \\ ${ }^{1}$ Institute of English Language and Literature, Sindh University, Jamshoro, Pakistan \\ ${ }^{2}$ National College of Business Administration \& Commerce, Lahore, Pakistan \\ ${ }^{3}$ HOD Arts and Humanities, KFUEIT, Rahimyar Khan, Pakistan \\ ${ }^{4}$ Department of Humanities, KFUEIT, Rahimyar Khan, Pakistan \\ ${ }^{5}$ M Phil Scholar in English, KFUEIT Rahimyar Khan, Pakistan \\ Correspondence: Syed Khuram Shahzad, Institute of English Language and Literature, Sindh University, \\ Jamshoro, Pakistan. E-mail: javed1387@gmail.com
}

Received: August 12, 2020

doi:10.5539/ijel.v10n6p287
Accepted: September 14, $2020 \quad$ Online Published: September 26, 2020

URL: https://doi.org/10.5539/ijel.v10n6p287

\begin{abstract}
This present research is about how the linguistic landscape brings about the promotion of language and public awareness. The linguistic landscape is a sociolinguistic phenomenon that is used for the promotion of language and culture as well. Linguistic landscape can be seen everywhere in the society as in advertisement billboards, traffic signboards, public awareness messages on the signboards, buildings, shopping centers, airports, etc. This study covers the dimension of traffic signboards and how they are consciously or unconsciously are promoting the language in Pakistan, especially the Urdu, the National language of Pakistan, English, the international language, the Mandarin, the language of China, and the Sign language. Two hundred and ten traffic signboards are selected for the completion of this research. The data collected from the traffic signboards of the motorways, highways of all the provinces of Pakistan. The purposive sampling technique is used for this study. This study will disclose how traffic signboards are promoting the language written over them, whether written or sing language. The data was analyzed through observation with the pictures of traffic signboards. The present study is qualitative in nature, so the data is analyzed and interpreted in the description form.
\end{abstract}

Keywords: promotion, sociolinguistics, landscape, awareness, signboards

\section{Introduction}

No one can escape from the range of the language. It is found everywhere, whether we notice it or not. It is not only in our conversations but also everywhere around us. It is with us while we are traveling, shopping, playing, walking, etc. it is also found in business or religious activities. In short, it is clung with us in every sphere of life. Language has also become a very powerful tool in business, politics, studies, governance, even in religion. Just walk into some town, city or market, you find much material written on buildings, airports, menus, shopping centers, parks, museums, etc. no place will be without wordings whether in the form of information or advertisement. Since with it start, the language has prevailed maximum in society in different shapes and forms, and still, it goes on. Therefore, it not static. It is the dynamic aspect of language that it goes on changing and adjusts itself according to the situation and needs of the times. It is so universal that every discipline of life has its own language terminology and effect. Everyone knows that the primary purpose of language is communication, but every discipline of field of life has its own bunch of knowledge in the form of vocabulary.

The phenomenon of the linguistic landscape is not an orthodox aspect of human language. It is directly connected to sociology, linguistics, psychology, applied linguistics, and other cultural studies and anthropology (Shohamy, Rafael, \& Barni, 2010). It is the term which is employed firstly by the Landry and Bourhis in 1997. According to them, the linguistic landscape is the language found on the buildings of the government, public signs, marketplaces, street names, and billboards. These all signs are combined to make and landscape of that area, region, or territory or urban accumulation (Landry \& Bourhis, 1997). The linguistic landscape is not limited 
in its scope. It has not the jurisdiction only to the signboards or advertisement; rather, it is the language that is found in the whole environment as in images, words in public places. Its purpose is to grasp the attention in the area referred to as the linguistic landscape (Shohamy \& Gorter, 2008).

The linguistic landscape follows the community wherever it goes and flourishes. It requires the attention of the people living in the community and wants an impact of remembrance upon them. It finds it place in every visible place or the area accumulated with human activities. In other words, it makes its own scenes in the streets, parks, billboards, or any visible place. It has not only promoted the language but also takes a new dimension in society called socio symbolism (Ben-Rafael, Shohamy, Hasan Amara, \& Trumper-Hecht, 2006). The sociolinguists employ the linguistic landscape and the other researchers that the language is not used only in the express communication but also used visually in multiannual societies. The same display can be found in the Amazonia to the huge metropolitan centers (Sebba, 2010a). For example, you can see some signboards in Hebrew, Arabic, and English in Jerusalem (Shulist, 2018).

Why is it called the 'linguistic landscape'? The answer is very simple that every space or area or piece of land where there exists a society it must be surrounded by the language, whether in the form of express interaction and communication by the people or in the symbolic form of signboards, advertisement boards, traffic instructions, etc. it must have a cover that space with its linguistic material. In the wider sense, it is the phenomenon of text and interaction where the readers and writers live in urban space, and it follows them whatever they do, whether read or travel. It is the very nature of the human that he does not live alone and make a community so he may live with the comfort with a sense of security. When a community is established, it has fundamental needs to be fulfilled. These are the very needs that drive human society. These needs further pave the way for the business, and then business takes its own run and needs some advertisement for its publicity. Now it is the same phenomenon of advertisement that develops further and adopts the shape of the linguistic landscape. It is also the inner urge in the human that he wants to show or declare whatever he has, and it is the human nature that listens or sees and then acts accordingly. These all human natures are the causes of the establishment of the linguistic landscape. In a sense, it is also called quite naturalistic.

\subsection{Traffic Signs}

There are various dimensions of the linguistic landscape. The traffic signals are one of them. The traffic signals are used not only to give information on how to behave on the road but also to the face of the community, its discipline, and its development. It is also the very nature of human beings that he wants security everywhere. Humans invented vehicles for his easement and time saving, but at the same time, it is the road on which he feels quite insecure due to the speed and hastily attitudes. He puts checks and control to make his journey or passage secure. They adopted the method of instructions in the form of sings and signals. As these signs and signals are for road safety and traffic control, so these are called traffic signals

Traffic signs or road signs are signs erected at the side of or above roads to give instructions or provide information to road users. Such pictorial signs use symbols (often silhouettes) in place of words and are usually based on international protocols. Such signs were first developed in Europe and have been adopted by most countries to varying degrees. With traffic volumes increasing since the 1930s, many countries have adopted pictorial signs or otherwise simplified and standardized their signs to overcome language barriers and enhance traffic safety. The earliest road signs were milestones, giving distance or direction; for example, the Romans erected stone columns throughout their empire, giving the distance to Rome. In the middle Ages, multidirectional signs at intersections became common, giving directions to cities and towns.

In 1686, King Peter II of Portugal established the first known Traffic Regulation Act in Europe. This act foresees the placement of priority signs in the narrowest streets of Lisbon, stating which traffic should back up to give way. One of these signs still exists at Salvador Street, in the neighborhood of Alfama.

The first modern road signs erected on a wide scale were designed for riders of high or "ordinary" bicycles in the late 1870 s and early $1880 \mathrm{~s}$. These machines were fast, silent, and their nature made them difficult to control; moreover, their riders traveled considerable distances and often preferred to tour on unfamiliar roads. For such riders, cycling organizations began to erect signs that warned of potential hazards ahead (particularly steep hills), rather than merely giving distance or directions to places, thereby contributing the sign type that defines "modern" traffic signs.

The concept of LL is not new but has been discovered for a long. LL is indeed the latest development of this century. However, its pieces of evidence are found back in history (Blommaert, 2013; Dhongde et al., 2002). Some previous on a precise form of LL was done in graveyards used by migrant societies (Francis, Kellaher, \& Neophytou, 2005). Different things have been discovered from the ruins of Harrapa, Mohanjo Daro and Texla 
(Pakistan), which are considered the oldest civilizations of the world, on which different pictures and signs have been drawn for communication purposes. Certain languages being engraved "long after the language ceased to be spoken" in the societies (VanDam, 2009). These people also draw figures and pictures on the wall to convey their messages. In modern world same thing is being used to convey messages and for communication purposes in markets, roads, localities, beaches, highways etc.

\section{Review of the Related Literature}

The linguistic landscape is a fascinating field and has attracted so many researchers due to its novelty and scope. They looked at it from different angles and dimensions, and still, the work is going on. Like language, it is also dynamic, adopts the variation according to the prevailing and demands of the society. The speed of the published work regarding LL is remarkable. The paradigm of LL is not orthodox and evolved rapidly in recent years. A lot of parameters and rules of LL are yet to be established. It has not ideological rules or basis yet (Sebba, 2010b). A lot of journals and issues have been devoted to this subject as the 'International Journal of Multilingualism' International Journal of Multilingualism and International journal of Sociology of Language the International Journal of Sociology of Language (Dmitrenko, 2017; Zabrodskaja \& Milani, 2014). Another journal, named as the "Journal of World Englishes". Another journal by John Benjamins named Linguistic Landscape: An International Journal was devoted to the subject of LL.

Along with this, there were so many academic conferences held for the Linguistic landscape (LOU, 2015). There is also a Bibliography which can be explored about linguistics landscape (Troyer, 2016; Troyer, 2013). There was another issue for the same purpose names as 'issue of Manusya that started with the history and the themes of the discipline' (Huebner, 2016; Vibulphol, 2016). The discipline of LL is a new one, so many things as methodologies and selection of the material, their categorization, analysis, presentation, and conclusions are still vague. Sometimes it seems to be quite controversial (Tufi \& Blackwood, 2010). Anyhow, it addresses the fundamental research questions as can the handmade signs be considered equal to the huge signs used by the commercials? It is a very interesting one that what signs should be considered in the realm of linguistic landscape and which should not be included in". What should be the language written within the signs and whether the language within the signs should be translated into the native language or not? What diction should be used in the linguistic landscape? Is there any specific or recommended style for it? How much visible should the signs be? What are the learning aspects of the linguistic landscape? These are some questions that are yet to be addressed. However, it does not mean that the linguistic landscape is confusing or difficult to understand, or there are factors those bring about its rejection. It is not very difficult but sensitive one because the signs are not detailing but a symbolic description. Moreover, these signs cannot be equally understood by all the viewers.

Firstly, there almost all the writers in their writings employ included plural languages technically in linguistic landscape and it. It was Papen who used this term beyond plural languages and imparted a new dimension to it by using it a public manner that was purely monolingual in the German city, and within it, the Heyd adopted it in English writing style and technique in which the reactions of the people were involved (Heyd, 2014; Papen, 2012). This shows the local relevancy of the language that is used in the public sings. In other words, the language used in the sings is proof of its local relevancy and acceptability (Hult, 2018). It is an admitted fact that the language that is not used is dead over time. It is the usage of any language that keeps it alive. No doubt, grammar and other structures of the language are important for its long life, but the most important is its usage. So, in this way, the phenomenon of the linguistic landscape becomes more important due to its multidimensional usage. Due to the linguistic landscape, the language is daily injected from the minds and eyes of the people consciously and unconsciously. People see these sings even they are in a hurry.

The phenomenon of the linguistic landscape becomes richer in the multilingual societies where it is used in quite unique and numerous styles. It means that if a country is multilingual, the signs will also be multilingual, and people become used to these signs very commonly, especially the merchants. the needs of the business of the merchants give life to the phenomenon of linguistic landscape, and their customers also recognize the sign of every product and note rapidly whenever any change happens with the signs of that product (Hult, 2014).

Pakistan is a multilingual country and is progressing as well. It has a lot of opportunities and momentum for not only business but also linguistic varieties. The literacy rate in Pakistan is also increasing day by day. There are many factors for the growth of its literacy. The traffic and road signs are in one of them. They are not mere pieces of decoration to make the location attractive rather, and they are for guiding, giving directions, warning, and instructing. The traffic accidents contribute a major part in the death rate of any country, so all the people must have in-depth knowledge of these traffic signals for not only their safety but also the safety of others as well. The traffic signals have become more significant in this regard. Pakistan is a multilingual country, and 
English is the mandatory subject in all government and public schools. Moreover, the official language of the country in practice is English, while the national language is Urdu. Both languages are taught in the school since the child starts his education in the school.

The traffic and the other advertisement signboards are in the pictorial, written, and symbolic form in Pakistan. These signs provide a rich vocabulary to the learners of the English language. It means that the phenomenon of the linguistic landscape is helpful equally in language learning and guidance. Vocabulary is the number of words that can be used while uttering a language-furthermore, the learning and practice of the language structure complete the language learning process. As society has developed in education, so now you can find separate books on public and road safety. To pass a driving test in Pakistan, it is mandatory to pass a paper having the syllabus of road and traffic signs along with an interview. If anybody fails in the paper, a driving license is not issued to him, and he is asked to come again after preparation.

Moreover, if you visit a factory, you can find signs regarding according to the factory and its relevant departments. In this sense, the road signs give much vocabulary to every person passing by the roads. This vocabulary not only enhances the vocabulary but also gives them the confidence to learn about that language in which that signboard is decorated or written. These are the nonlinguistic way of communication. Every sign provides some information and makes a basic unit. These include the signs and symbols and pictorial instructions to convey the condition of the roads (Dewar, 2014; MacGregor, 2003). These instructions include the corners, bends, bumps, intercession, and T. Junctions. The other is the directions about caution regarding speed limit, road routes, and other precautionary steps to ensure safety on roads. The essence of the linguistic landscape is attached to the space that is comprised of symbols having the information and instructions for the road passer regardless of their nativity or regions. This is called emplacement (Scollon, 2003). The signs cannot be displayed at an empty place but put at some specific and visible space that is called the place of semiotic. In other words, the signs have meanings according to their placement in some locations. It is also a question of common sense that when someone is placing an important sign having the worth of information and lifesaving instructions, why these will be displayed on some unseen or invisible locations.

If we go on deep, we will see that the traffic signals are not mere signs but have international significance because they are the universal traffic codes understood and interpreted by all over the world. If we live in any region of the world and travel to some country whose language and culture are unknown to us, yet we will understand the traffic signals put on the roads of that country. It is the universality of the signs and symbols of the traffic. For example, the 'zebra crossing' on the road is very known to everyone, even he or she is illiterate.

Pakistan is the fifth largest country by population in the world and is developing day by day in economy and literacy as well. She has a long plan with China called 'one belt, one road initiative' (Clarke, 2017) or CPEC (China Pak Economic Corridor). It is a plan in which a huge road network will be spread in Pakistan crossing almost the whole country with the partnership of China. It is an obvious and live example of the linguistic landscape. It is understood that where there are roads, there will be traffic signs and symbols. The important thing is that the people of both the countries will not only make these roads but after completion of its all phases, will also travel, which means that the three language English as an international language, Urdu, the Pakistan National language, and the Mandarin, the Chinese language will be displayed on the roots have traffic symbols. The phenomenon of the linguistic landscape will promote three languages at a time.

Moreover, the 'one belt, one road initiative' by China is not limited to Pakistan only. It will pass through seventy countries around the world, including Asia and Europe (Dunford \& Liu, 2019; Hurley, Morris, \& Portelance, 2019). The signs and symbols will be displayed on all the routes of those countries along with the Mandarin.

Through traffic signs, the phenomenon of the linguistic landscape takes the turn to the ideology of language and power. China is the emerging superpower across the world that has prevailing her diplomacy through economics. She has different projects with massive countries of the world, including all the continents. She is also influencing the internal and external policies of those countries and through her 'one belt one road project' constructing roads as well. The language of one country present in some other countries via any medium means the virtual presence of that country there. The same language and power concept had prevailed when the colonial powers like British, France, Portuguese, and Japan made colonized the countries of Asia like United India, Indonesia, China, etc. they dominated these countries and built infrastructures and spread their languages there.

\section{Research Methodology}

\subsection{Population}

There were numerous traffic signboards across the world. However, the researcher selected only fifty each from 
all the four provinces of Pakistan and twenty from the authentic web source for the fulfillment of the purpose of the study.

\subsection{Data Collection}

The data collected from the traffic signboards of the motorways, highways of all the provinces of Pakistan. For the study, the researcher selected the pictures of fifty traffic signboards. In comparison, pictures of some relevant traffic signboards were drawn from authentic internet sources.

\subsection{Sampling Technique}

The participant observation technique took the data. The purposive and convenient sampling technique was adopted to collect the data.

\subsection{Samples}

Table 1. Samples collection

\begin{tabular}{ll}
\hline Province of Pakistan & Number of signboards \\
\hline Punjab & 50 \\
Sindh & 50 \\
KPK & 50 \\
Baluchistan & 50 \\
Internet/Web sources & 20 \\
Total & 220 \\
\hline
\end{tabular}

\subsection{Data Analysis}

The data analyzed and interpreted through observation according to nature and message on the traffic signboards. The wording, pictures, and sings were interpreted with the dimension of promotion languages over them and public awareness. As this is a qualitative study, the purposive and convenient sampling technique is adopted to collect the data.

\subsection{Delimitation}

For the easement and quality of research, the researcher made limited this study to only traffic signboards majorly across Pakistan.

\section{Data Analysis and Findings}

The linguistic landscape is purely a sociolinguistic phenomenon. It is not a separate field of linguistic as sociolinguistic or psycholinguistics or discourse etc., as language is a sociolinguistic phenomenon and covers the whole society. Society is derived through language. No society can exist without language. There are different types of language as spoken, written, and sign. When we go out of home, we saw different signboards across the roads. These are of different sorts and nature. Some are advertisement boards, some having information, others have instructions while some have instructions and warning on them. Among them, there are traffic signboards having traffic signs, directions, information, and warnings. These boards are written in a language or language according to the territory and locations. The traffic signboards promote the language or languages in which they are written to. The language can be written or spoken sign. The traffic signboards are displayed in written and sign language. 


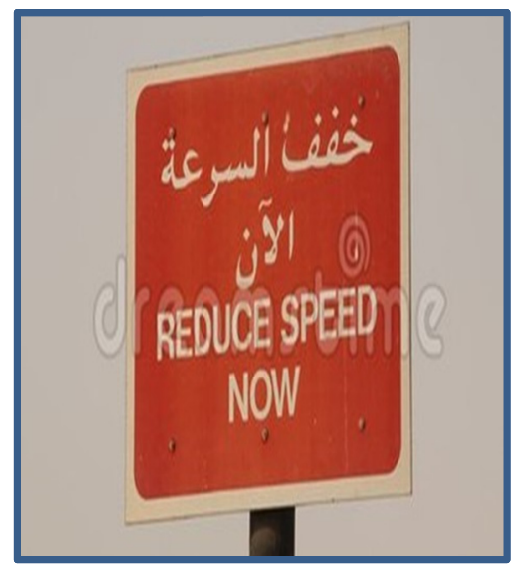

Figure 1. dreamstime.com

The traffic signs no doubt bring about the promotion of a language or language. These are found everywhere these days as the society is developed enough to display the traffic signs. Almost all the countries of the world, whether backward, progressing, or developed, have the traffic control system and have conducted traffic signboards for the road safety of the road users. These signboards are displayed in the native, national, or international languages. The signboard mentioned above is displayed in English and Arabic languages. English is an international language, while Arabic the national language in Arabic countries. There is no compulsion of literacy in understanding the traffic signboards. There is a common-sense required for understanding the traffic signs. These days every country is trying to enhance her literacy rate, so the traffic signboards have not the tough language to read or understand. Even the language becomes very easy due to the explanatory signs on them. The photo is promoting the two languages like Arabic and English. There is also an instruction on the signboard "Reduced speed now". The simple sentence means drive slowly. The persons who do not know about the English wholly will interact with it when he has a view of the above signboards. Moreover, these signboards are erected on some conspicuous palace, so everyone on the road has a look over them, even unintentionally.

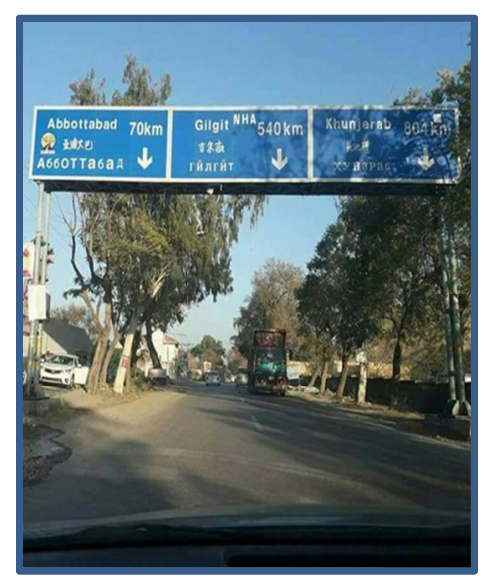

Figure 2. Punjab, Hasan Abdal

The selected traffic signboard has been taken from the Province Khyber Pakhtunkhwa in Pakistan. This signboard is written in English and Mandarin. The native languages of Province Khyber Pakhtunkhwa are 'Pashto, Urdu, and Hindko' while the signboard is written in English and Mandarin. Here English has been promoting as an 'international language' while the Mandarin is written as China is the major business partner with Pakistan through 'CPEC' having an investment of nearly 50 billion US\$ in Pakistan. Moreover, a huge number of Chinese engineers are working along with Pakistani Engineers. These signboards are not only for citizens of Pakistan but also for the people of China visiting Pakistan for their projects. In this way, the Mandarin is also being promoted through traffic signboards. Another interesting fact is there that like English, which is an 
international language, the digits are also recognized by all the people of the world regardless of their region and language. China is a friend of Pakistan and now a major business partner as well, so in this way, he has been influencing Pakistan through her products, soft power, and now through language and culture as well. The citizen of Pakistan of the selected locality interacts with traffic signboards daily while travel on this road and saw the Mandarin language. Most of the private institutions in Pakistan have started to teach Mandarin to have an eye on the future.

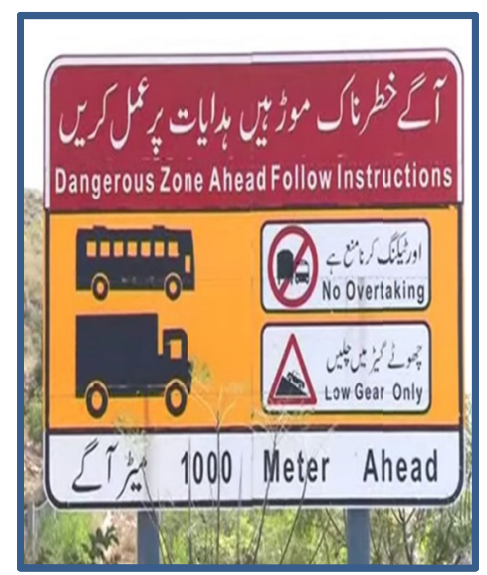

Figure 3. National Highway, Sindh Province

The selected traffic sign has taken from the M- Motorway project from the province of Punjab in Pakistan. This is very important that the motorway is 375 -kilometer-long and connects Islamabad to Lahore. It is a high-speed motorway among the five top high speeds motorways in the world. The currently selected traffic sign promoting the three languages at a time Sign language understood pragmatically by all, the English language, the international language, and Urdu, the national language of Pakistan. These traffic signboards have not only three languages at a time in it but also has some warnings and instructions for road safety. It is the beauty or vastness of the traffic signboards that we cannot find three languages at a time anywhere except the traffic signboards. In other words, traffic signboards are the best tools for promoting language or languages. Here is a sentence in this signboard in Urdu as 'agay Khatarnaak more hain Hadayat per amal karain' translated in English as 'Dangerous Zone ahead follow the instructions' And in Urdu' overtaking karna mana hai, translated in English as 'No overtaking' and in Urdu 'chotay gear main chalain' translated in English as 'low Gear only'. The messages behind these instructions in both languages are that 'reduce speed and drive more carefully.' Moreover, the selected signboard is not only promoting the languages Urdu and English but also a translation of one another. Everyone who wants to learn Urdu from English or English from Urdu can learn the vocabulary and sentence structure at the same time through this signboard. It means that the signboards bring about the promotion of languages along with the learning of those languages as well.

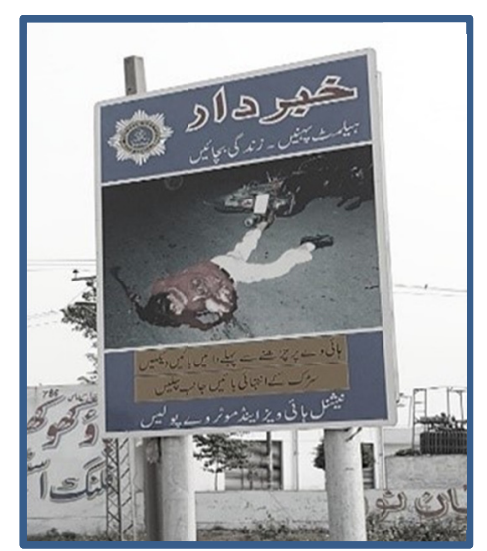

Figure 4. National Highway, Baluchistan Province 
The National Highways and Motorway Police in Pakistan install the selected signboard. This signboard is promoting the Urdu language that is the National language of Pakistan. This traffic sign can be seen at many spots across the motorways and highways in Pakistan, having the Loge of Highways Authority. The notable thing about this signboard is that it is only in Urdu, the National language of Pakistan, and not in English, the international language. Although there are many signboards installed by the National Highways and Motorways Police, which are in Urdu along with English, and there are some traffic signs, universally known. It is a unique signboard as it is written in Urdu and a real accident photo on it. The message on this selected traffic signboard is so important that it is displayed only in the National language of Pakistan or the language that is read and understood by across the country. This is a promotion of the National language of Pakistan. This unique type of language is special for urging people to follow the safety instructions by the traffic department. Besides, the universal phenomenon people first see then believe, so this signboard is demonstrating the real accident that is producing a precautionary impact on the minds of the people. The message in the selected signboard is 'to wear a helmet and save a life.' The selected signboard is not only promoting the Urdu language but also has a psychological appeal to people to wear the helmet to save their lives. The traffic signboards bring about the promotion of language as these do not use rich vocabulary or complex structures rather use objective words and simple directions. In other words, these boards follow the doctrine of 'economy of words' in a language.

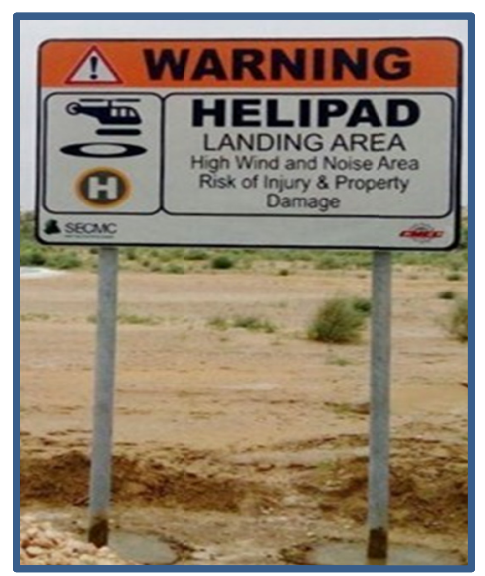

Figure 5. Khyber Pakhtunkhwa, Peshawar Cantt

This signboard is very important and having sensitive information and instruction. It is written in the international language. Urdu is the national language of Pakistan, but this board has been written in English along with signs as well, so if a man is unable to read English, he may understand the sensitivity of the area through signs. In other words, some common sense or a little pragmatic quality is also required to grasp the message in the signboard. Moreover, this signboard that is written in international language while the National language of Pakistan is Urdu, it means that this signboard is not only promoting the English as an international language but also promoting the phenomenon of 'bilingualism'. The traffic signboards promote awareness along with the promotion of language as well. It is not a common type of signboard erected around common high or motorways. It is a signboard conducted near an airport having warning instructions that the nearby area of the airport and very near to the helipad. This is unique in its location where it is situated and message. There are common messages on almost all the motorways and highways like 'reduce speed', wear helmet 'population ahead' etc. while the message on this signboard is a unique one as there is written that 'high noise and wind area' and 'risk of injury and property damage.' This means that it is an area that is not a thoroughfare and high risk here.

\section{Discussion}

Language is a sociolinguistic phenomenon and one of the major drivers of society. It covers the whole society drives it as well. No society can exist without language. The language has different types as spoken, written, etc. it performs different functions as well as communication, promotion or advertisement, information, direction, entertainment, expression, and awareness. It has existed everywhere in the texts, speeches, signboards, billboards, traffic signs, advertisements, etc. in other words, and it has prevailed in almost all the sectors of life. It is existed in words, signs, symbols, and the minds of the people. It is also a psychological fact that people pay more 
attention to objective things rather than subjective. For example, the people will see a snap or picture and will not read detail. This fact becomes stronger when such things are displayed on roads when people are always hurried. That is why the phenomenon of LL gets more importance. All the traffic signboards are displayed objectively in the short written or pictorial or both forms. There is also a psychological fact that when we read or see something repeatedly, that leaves an unconscious effect upon us, and we start to understand that silently. The study is about an important and universal phenomenon of a linguistic landscape that is a wide dimension of language and not a separate field of it. It is a sociolinguistic phenomenon, and society is directly involved in it.

There is the various dimension of the linguistic landscape as well as advertisement boards, general instructions. Locations boards, warning boards, traffic signboards etc. this study about the 'linguistic landscape phenomenon about traffic road signs' in terms of 'promotion of language and awareness'. A crucial study not only took a different aspect of the linguistic landscape but also tried to cover the situation as well. The traffic signboards are a very effective and unique way of promotion of language as they catch the attention of the public directly. They are located at some conspicuous place and have visible and bold font writings. So, these are used to perform various important functions as creating awareness among the people. Therefore, they are used heavily for product advertisement and promotion of the language. They promote not only the international and regional national languages but also sign languages as well. At the same time, they enhance the vocabulary, pragmatic quality, and awareness among the people.

\section{Conclusions}

Pakistan is a multilingual country. It is also an interesting fact that almost all her different provinces have the names on the local languages as Punjab from the Punjabi language, Sindh from the Sindhi language, Baluchistan from the Balouchi language, and Khyber Pakhtunkhwa from the Pashto language. It means that it is a country based on purely linguistic grounds. Moreover, they are culturally diverse, as well (Shah \& Amjad, 2011). This study portrayed the phenomenon of LL in two aspects. Commonly, it explored that the phenomenon of LL brings about the promotion of language in which the traffic signboards are written, whether in English, Arabic, Mandarin, or Urdu. Secondly, is enhanced the awareness of the phenomenon of LL in the Pakistani context.

No doubt, Pakistan is a progressing country for many years, and it has deep geographical importance, and it is also a neighbor and friend of China. China is the emerging superpower in terms of economics, and she has launched a project named 'one belt one road initiative' across so many countries, and when it goes through Pakistan, it is called CPEC (China Pak Economic Corridor). Through this project, China will construct the road, railway lines, and even airports in Pakistan. In other words, the CPEC is going to change almost all infrastructure of Pakistan in terms of roads and economy. Pakistan is also a progressing country regarding her economy and struggling to grow her economic conditions. Pakistan is among those countries that have geographical importance across the world. By realizing this importance, she is building road infrastructure for the business easement.

Further, China, the emerging world superpower, has a trade business with Pakistan through a huge road network called CPEC (China Pak Economic Corridor). Through this road network, including motorways, highways, railway stations, and airports, will be built across Pakistan. Surely, this infrastructure has all types of signboards accordingly. There is written Urdu, English, Sign, and Mandarin languages on approximately all signboards. In other words, these languages will be promoted through this road initiative. The traffic signboards are unique also that they do not use superfluous or redundant words over them rather consume minimum words. They act upon the 'economy of words' rule. The people of Pakistan are feeling the influence of China not only on their country but also all over the world, so they do understand the prevailing of the Mandarin language as the guarantee of their future. They make a resemblance of it with the English historically in this region. Therefore, most of the people of Pakistan have started to take the learning classes of Mandarin. The study showed that the phenomenon of Linguistic landscape prevails not only the awareness in public but also bring about the promotion of language in which they are written or displayed. Pakistan is constructing roads and highways with the help of China, and it is surely promoting the phenomenon of LL. This phenomenon will enhance awareness and understanding of English. Urdu and Mandarin in the people of Pakistan. Now, most of the people in Pakistan have started to learn Mandarin for their future security as well.

\section{Recommendations}

The linguistic landscape is a vast and multidimensional area of study. Single research is not enough to do justice with this topic. The researcher tried his level best to justify the discipline, but there are so many dimensions left that are yet to be touched. Where there are communities or societies, there will be signboards of every type. Therefore, further research on this unique area has been free to do research. 


\section{References}

Ben-Rafael, E., Shohamy, E., Hasan Amara, M., \& Trumper-Hecht, N. (2006). Linguistic landscape as symbolic construction of the public space: The case of Israel. International Journal of Multilingualism, 3(1), 7-30. https://doi.org/10.1080/14790710608668383

Blommaert, J. (2013). Ethnography, superdiversity and linguistic landscapes: Chronicles of complexity (Vol. 18). Multilingual Matters. https://doi.org/10.21832/9781783090419

Clarke, M. (2017). The belt and road initiative: China's new grand strategy? Asia Policy, 24, 71-79. https://doi.org/10.1353/asp.2017.0023

Dewar, R. E. (2014). Early human settlers and their impact on Madagascar's landscapes. In IR Scales (Ed.), Conservation and Environmental Management in Madagascar (pp. 44-64).

Dhongde, R., Ramamoorthy, L., Naik, A. K., Somayaji, H. P., Sachdeva, R., Gnanasundaram, V., ... Subbarao, K. V. (2002). Languages in India-Their Status and Functions Lachman M. Khubchandani Language Profiles of Jharkhand, Chhattisgarh and Uttaranchal: A Subaltern Perspective of Language Development. Paper presented at the Linguistic Landscaping in India: With Particular Reference to the New States: Proceedings of a Seminar.

Dmitrenko, V. (2017). Language learning strategies of multilingual adults learning additional languages. International Journal of Multilingualism, 14(1), 6-22. https://doi.org/10.1080/14790718.2017.1258978

Dunford, M., \& Liu, W. (2019). Chinese perspectives on the Belt and Road Initiative. Cambridge Journal of Regions, Economy and Society, 12(1), 145-167. https://doi.org/10.1093/cjres/rsy032

Francis, D., Kellaher, L., \& Neophytou, G. (2005). The Secret Cemetery. Berg: Oxford.

Heyd, T. (2014). Folk-linguistic landscapes: The visual semiotics of digital enregisterment. Language in Society, 43(5), 489-514. https://doi.org/10.1017/S0047404514000530

Huebner, T. (2016). Linguistic landscape: history, trajectory and pedagogy. Journal of Humanities, 19(3), 1-11. https://doi.org/10.1163/26659077-01903001

Hult, F. (2018). Language policy and planning and linguistic landscapes. In Oxford handbook of language policy and planning (pp. 333-351). https://doi.org/10.1093/oxfordhb/9780190458898.013.35

Hult, F. M. (2014). Drive-thru linguistic landscaping: Constructing a linguistically dominant place in a bilingual space. International Journal of Bilingualism, 18(5), 507-523. https://doi.org/10.1177/1367006913484206

Hurley, J., Morris, S., \& Portelance, G. (2019). Examining the debt implications of the Belt and Road Initiative from a policy perspective. Journal of Infrastructure, Policy and Development, 3(1), 139-175. https://doi.org/10.24294/jipd.v3i1.1123

Landry, R., \& Bourhis, R. Y. (1997). Linguistic landscape and ethnolinguistic vitality: An empirical study. Journal of Language and Social Psychology, 16(1), 23-49. https://doi.org/10.1177/0261927X970161002

LOU, J. J. (2015). Imagining Place Through Linguistic Landscape: Silent Signs of Resistance in Nga Tsin Wai Village, Hong Kong. Paper presented at the Linguistic Landscapes 7.

MacGregor, L. (2003). The language of shop signs in Tokyo. English Today, 19(1), 18-23. https://doi.org/10.1017/S0266078403001020

Papen, U. (2012). Commercial discourses, gentrification and citizens' protest: The linguistic landscape of Prenzlauer Berg, Berlin 1. Journal of Sociolinguistics, 16(1), 56-80. https://doi.org/10.1111/j.1467-9841.2011.00518.x

Scollon, S. (2003). Body idiom in platform events: Media representation and the hegemony of the vicarious conversation. Social Semiotics, 13(1), 89-102. https://doi.org/10.1080/1035033032000133526

Sebba, M. (2010a). Discourses in transit. In A. Jaworski \& C. Thurlow (Eds.), Semiotic landscapes: Language, image, space (pp. 59-76).

Sebba, M. (2010b). Linguistic Landscapes: A Comparative Study of Urban Multilingualism in Tokyo Peter Backhaus. Writing Systems Research, 2(1), 73-76. https://doi.org/10.1093/wsr/wsp006

Shah, S. A. M., \& Amjad, S. (2011). Cultural diversity in Pakistan: national vs provincial. Mediterranean Journal of Social Sciences, 2(2), 331-344.

Shohamy, E., \& Gorter, D. (2008). Linguistic landscape: Expanding the scenery. Routledge. 
https://doi.org/10.4324/9780203930960

Shohamy, E. G., Rafael, E. B., \& Barni, M. (2010). Linguistic landscape in the city. Multilingual Matters. https://doi.org/10.21832/9781847692993

Shulist, S. (2018). Signs of status: language policy, revitalization, and visibility in urban Amazonia. Language Policy, 17(4), 523-543. https://doi.org/10.1007/s10993-017-9453-3

Troyer, R. (2016). Robert Blackwood, Elizabeth Lanza, and Hirut Woldemariam (Eds.). Negotiating and Contesting Identities in Linguistic Landscapes. London: Bloomsbury Publishing. 2016. 288 pages. Journal of Humanities, 19(3), 88-93. https://doi.org/10.1163/26659077-01903007

Troyer, R. A. (2013). Linguistic Landscape Bibliography. Zotero public group.

Tufi, S., \& Blackwood, R. (2010). Trademarks in the linguistic landscape: Methodological and theoretical challenges in qualifying brand names in the public space. International Journal of Multilingualism, 7(3), 197-210. https://doi.org/10.1080/14790710903568417

VanDam, K. (2009). Dutch-American language shift: Evidence from the grave. Paper presented at the The LACUS forum.

Vibulphol, J. (2016). Students' Motivation and Learning and Teachers' Motivational Strategies in English Classrooms in Thailand. English Language Teaching, 9(4), 64-75. https://doi.org/10.5539/elt.v9n4p64

Zabrodskaja, A., \& Milani, T. M. (2014). Signs in context: Multilingual and multimodal texts in semiotic space. International Journal of the Sociology of Language, 2014(228), 1-6. https://doi.org/10.1515/ijsl-2014-0002

\section{Copyrights}

Copyright for this article is retained by the author, with first publication rights granted to the journal.

This is an open-access article distributed under the terms and conditions of the Creative Commons Attribution license (http://creativecommons.org/licenses/by/4.0/). 